\title{
Altered profile of circulating microparticles in rheumatoid arthritis patients
}

Javier Rodríguez-Carrio*, Mercedes Alperi-López†, Patricia López*, Sara Alonso-Castro†, Santiago R. Carro-Esteban*, Francisco J. Ballina-García† and Ana Suárez*

*Area of Immunology, Department of Functional Biology, University of Oviedo, Asturias, Spain

†Department of Rheumatology, Hospital Universitario Central de Asturias, Asturias, Spain

\begin{abstract}
Microparticles (MPs) could be considered biomarkers of cell damage and activation as well as novel signalling structures. Since rheumatoid arthritis (RA) is characterized by immune and endothelial activation, the main aim of the present study was to analyse MP counts in RA patients. Citrated-blood samples were obtained from 114 RA patients, 33 healthy controls $(\mathrm{HC})$ and 72 individuals with marked cardiovascular (CV) risk without autoimmune manifestations (CVR). MPs were analysed in platelet-poor plasma (PPP) and different subsets were identified by their surface markers: platelet- $\left(\mathrm{CD} 41^{+}\right)$, endothelial- $\left(\mathrm{CD} 146^{+}\right)$, granulocyte- $\left(\mathrm{CD} 66^{+}\right)$, monocyte- $\left(\mathrm{CD} 14^{+}\right)$and Tang-derived $\left(\mathrm{CD}^{+} \mathrm{CD} 31^{+}\right)$. Disease activity (DAS28), clinical and immunological parameters as well as traditional CV risk factors (diabetes, hypertension, dyslipidemia and obesity) were registered from clinical records and all data were integrated using Principal Component Analysis (PCA). Absolute MP number was increased in RA patients compared with $\mathrm{HC}$ and positively correlated with traditional CV risk factors, similar to that of CVR subjects. In addition, frequency of the different MP subsets was different in RA patients and significantly associated to disease features. Moreover, in vitro assays revealed that MPs isolated from RA patients were able to promote endothelial activation and exhibited detrimental effects on HMEC-I endothelial cell functionality. Circulating MPs from RA patients displayed quantitative and qualitative alterations that are the result of both disease-specific and traditional $\mathrm{CV}$ risk factors. Accordingly, this MP pool exhibited in vitro detrimental effects on endothelial cells, thus supporting their role as biomarkers of vascular damage.
\end{abstract}

Key words: angiogenic T-cell, cardiovascular risk factor, endothelial damage, microparticle, rheumatoid arthritis

\section{INTRODUCTION}

Microparticles (MPs) are small membrane vesicles $(0.1-1.0 \mu \mathrm{m})$ constitutively released by many cell types under physiologically conditions, but enhanced in many pathological situations, mainly associated with cell damage. Largely considered as inert cell debris, recent studies have demonstrated they could have a role in intercellular communication [1]. They have been demonstrated to harbour nucleic acids, signalling molecules, cytokines and even organelles, thereby supporting their active role in cell biology $[2,3]$. These facts have led to more attention being focused on MPs, since they could exert different effects depending on the conditions under they were originated as well as on the cell type from which they have released. Accordingly, MPs exhibit an array of surface markers derived from their parental cell that can be used to assess their origin [4].

Increased levels of MPs have been reported in patients with malignancies, infections, systemic inflammation, autoimmune and vascular diseases, among other pathological states [5]. Thus, circulating MPs have been commonly considered as biomarkers of injury, since they originate after cell activation and apoptosis, or are actively released upon specific activating receptors signals $[2,6]$. This is especially relevant in the context of cardiovascular (CV) disease, since MPs derived from different cell types implicated in the etiopathology of the disease (endothelial cells, lymphocytes, monocytes, smooth muscle cells and platelets) have been found increased in patients [7,8]. Actually, MPs from platelets and endothelial cells are proposed to play a role

Abbreviations: BMI, body mass index; CV, cardiovascular; CVR, cardiovascular risk; EMP, endothelial-derived MP; ESR, erythrocyte sedimentation rate; GMP, granulocyte-derived MP; HC, healthy controls; MoMP, monocyte-derived MP; MP, microparticle; PCA, Principal Component Analysis; PMP, platelet-derived MP; PPP, platelet-poor plasma; PRP, platelet-rich plasma; RA, rheumatoid arthritis; Tang, angiogenic T-cell; Tang-MP, Tang-derived MPs; TNF $\alpha$, tumour necrosis factor $\alpha$; VPD, Violet Proliferation Dye 450.

Correspondence: Dr Ana Suárez (email anasua@uniovi.es). 
in thrombogenesis as well as in endothelial activation $[9,10]$. Moreover, platelet-derived MPs are known to be able to activate neutrophils [1112], thereby promoting an innate immune activation that leads to neutrophil extracellular traps (NET) formation [13]. These mechanisms are also involved in vascular damage, thus supporting the link between MPs, inflammation and CV disease. In fact, the chronic inflammation associated with many autoimmune disorders could underlie the increased prevalence of $\mathrm{CV}$ events reported in these patients $[14,15]$. However, the role played by MP subsets in these situations remains unknown. Therefore, knowledge of these events could help to identify patients at risk and improve specific therapies. Additionally, they represent accessible and valuable biomarkers of different tissues (especially the vasculature) that are difficult to reach and study.

Taking into account these considerations, rheumatoid arthritis (RA), an autoimmune condition in which both immune and endothelial activation can be found, provides an interesting scenario to analyse MPs subsets. Previous evidence is limited and results concerning disease associations and MP subsets are heterogeneous (reviewed in [1]). A plausible explanation to account for these discrepancies, also found in other pathologies, is the lack of standardized protocols to analyse MPs. Because of their small size and the large heterogeneity of plasma MPs, most studies are performed by flow cytometry, although other methods have also been used. Traditionally, MPs had been identified by annexin V-binding in their surface [16], but recent evidence has brought into question this methodology, since annexin V-negative MPs express specific surface markers $[17,18]$ and have been reported to have clinical relevance [19]. Consequently, many authors have chosen different approaches to avoid annexin staining, such as MP total labelling [20] or no labelling [4].

With the aim of estimating the contribution of MPs to RA pathogenesis, this work simultaneously analysed total and platelet-, endothelial-, granulocyte- and monocyte-derived MPs in relation to disease-specific parameters as well as traditional $\mathrm{CV}$ risk factors. In addition, since we have recently proposed a role for angiogenic T-cells (Tang) in RA [21], we aimed to evaluate whether Tang-derived MPs can be found and if associations with clinical parameters could provide new insights on this T-cell subset. Finally, in vitro studies were performed to estimate the potential deleterious effect of RA-MPs on vascular endothelium.

\section{MATERIALS AND METHODS}

\section{Patients}

We conducted a case-control study involving 114 RA patients fulfilling the 2010 American College of Rheumatology RA criteria, consecutively recruited from the Department of Rheumatology (Hospital Universitario Central de Asturias, Oviedo). Routine clinical examination, including DAS28 calculation, was performed at the time of sampling. Medical records were revised in order to register clinical and immunological parameters, medications, traditional $\mathrm{CV}$ risk factors and previous $\mathrm{CV}$ events. Definition and classification of $\mathrm{CV}$ events and traditional risk factors (hypertension, diabetes, dyslipidemia, obesity and smoking) were performed as previously established [22,23].

Simultaneously, 33 healthy volunteers within the similar age range and gender than patients were recruited from the same population, and a group of 72 individuals with different traditional $\mathrm{CV}$ risk factors were recruited from their primary care referral centre (Table 1).

Automatized complete blood count and serum lipids analysis were carried out for all the participants. Approval for the study was obtained from the Regional Ethics Committee for Clinical Investigation, in compliance with the Declaration of Helsinki. All the participants gave written informed consent prior to study inclusion.

\section{Blood sampling and isolation of platelet-poor plasma}

A fasting blood sample was obtained by venipuncture in $4.5 \mathrm{ml}$ citrate-containing tubes (BD Vacutainer), which were transferred to the laboratory and centrifuged at $3000 \mathrm{~g}$ for $15 \mathrm{~min}$ at room temperature to obtain platelet-poor plasma (PPP) within a maximum of $2 \mathrm{~h}$ after blood collection. The resulting plasma was divided in three aliquots and stored at $-80^{\circ} \mathrm{C}$ until analysis.

\section{Analysis of MPs by flow cytometry}

PPP aliquots were thawed at room temperature and $200 \mu 1$ were transferred into new tubes and centrifuged at $13000 \mathrm{rpm}$ for $30 \mathrm{~min}$ at $15^{\circ} \mathrm{C}$. Then, the upper $180 \mu \mathrm{l}$ were carefully discarded and initial volume was restored with $0.22 \mu \mathrm{m}$ doublefiltered PBS. To identify cell-derived MPs, a Violet Proliferation Dye 450 (VPD, BD Biosciences) staining was performed, thus avoiding annexin $\mathrm{V}$ limitations [24]. Hence, $150 \mu 1$ were transferred into a new tube, brought to a final volume of $1 \mathrm{ml}$ with double-filtered PBS and $1 \mu \mathrm{l}$ of $1 \mathrm{mM}$ VPD was added. After incubation at $37^{\circ} \mathrm{C}$ for $15 \mathrm{~min}$, staining was stopped by placing the samples immediately on ice for $20 \mathrm{~min}$. Finally, VPD-stained MP suspensions were divided into different tubes and pairs of antibodies were added to identify specific MP subsets: anti-CD41-FITC (Immunostep, Spain) and anti-CD146APC (Miltenyi Biotech, Germany); anti-CD14-PE (Miltenyi) and anti-CD66b-APC (BD); anti-CD3-APC (Immunostep) and anti-CD31-PE (Immunostep). Antibodies were previously centrifuged $\left(13000 \mathrm{rpm}, 10 \mathrm{~min}, 4^{\circ} \mathrm{C}\right)$ in order to avoid aggregates [25]. Incubation was performed at room temperature for $15 \mathrm{~min}$ and then MP suspensions were transferred into Stepcount tubes (Immunostep), which allow absolute quantification. Tubes were immediately processed by flow cytometry.

Samples were analysed in a FACS Canto II flow cytometer. Forward scatter (FSC) and side scatter (SSC) were adjusted to logarithmic gain. MP gate was designed according to latex microbeads (Sigma-Aldrich) and confirmed with platelet-rich plasma (PRP) [26], setting 1.1 and $0.3 \mu \mathrm{m}$ as the upper and lower detection limits. Below $0.3 \mu \mathrm{m}$, only debris seemed to be detected after analysing double-filtered PBS. Unstained MPs were used to set the threshold for VPD-positive signal and unstained negative control of VPD-stained MPs to establish specific antibody fluorescence. No spillover between VPD and the fluorochromes assayed was registered. Acquisition was performed until 


\section{Table 1 Demographic and clinical parameters of RA patients}

Categorical variables are summarized as numbers (percentage), and continuous variables as medians (interquartile range) unless otherwise as stated ${ }^{*}\left[\right.$ median (range)]. a $P$ value $<0.01$ (HC compared with RA: $P=0.696$ ). ${ }^{b} P$ value $<0.01(C V R$ compared with RA: $P=0.460$ ). DAS28, disease activity score (28 joints); HAQ, Health Assessment Questionnaire; RF, rheumatoid factor; $\alpha \mathrm{CCP}$, cyclic citrullinated peptide antibody; ANA, antinuclear antibody. Differences were assessed by Kruskal-Wallis and Dunn-Bonferroni multiple comparisons tests and chi-square test, as appropriate.

\begin{tabular}{|c|c|c|c|}
\hline & HC $(n=33)$ & CVR $(n=72)$ & RA patients $(n=114)$ \\
\hline Gender (female:male) ( $n$ ) & $25: 8$ & $38: 34^{a}$ & 90:24 \\
\hline Age at sampling (years)* & $44.29(23-72)^{b}$ & $57.41(33-69)$ & $55.04(22-87)$ \\
\hline Disease duration (years) & & & $4.91(7.19)$ \\
\hline Age at diagnosis (years) & & & $48.41(14.62)$ \\
\hline Tender joint count & & & $2.00(6.00)$ \\
\hline Swollen joint count & & & $1.00(4.00)$ \\
\hline Patient global assessment (0-100) & & & $40.00(41.25)$ \\
\hline $\operatorname{ESR}(\mathrm{mm} / \mathrm{h})$ & & & $15.50(23.00)$ \\
\hline Patient pain assessment (0-10) & & & $4.00(4.00)$ \\
\hline $\operatorname{ANA}(+)(n)$ & & & $58(50.8 \%)$ \\
\hline Shared epitope $(n)$ & & & $47(41.2 \%)$ \\
\hline Erosive disease $(n)$ & & & $49(42.9 \%)$ \\
\hline \multicolumn{4}{|l|}{ Traditional CV risk factors $(n)$} \\
\hline Dyslipidaemia & & & $40(35.3 \%)$ \\
\hline Hypertension & & & $38(33.3 \%)$ \\
\hline Diabetes (Type 2) & & & $9(7.8 \%)$ \\
\hline Obesity (BMI > 30) & & & $22(19.3 \%)$ \\
\hline Smoking habit & & & $38(33.3 \%)$ \\
\hline Methotrexate & & & $80(70.1 \%)$ \\
\hline TNF $\alpha$ blockers & & & $45(39.4 \%)$ \\
\hline Tocilizumab & & & $12(10.5 \%)$ \\
\hline Statins & & & $20(17.5 \%)$ \\
\hline
\end{tabular}

10000 microbeads from Stepcount tubes were acquired $(<4 \mathrm{~min} / \mathrm{tube})$ at medium rate. All samples were processed and analysed batchwise to minimize technical variations.

Total and subset specific cell-derived MPs (absolute number/ml plasma) were calculated according to the MP counts acquired, the total number of microbeads from Stepcount tubes and the dilution performed during sample preparation.

\section{Q1 In vitro assays with HMEC-I cells}

The in vitro effects of plasma-isolated MPs on endothelium were evaluated using HMEC-I cells. To this end, pooled MPs suspensions from healthy controls (HC), cardiovascular risk (CVR) individuals and RA patients were prepared from ten representative subjects of each group (HC: $1.85 \times 10^{6}$ total MPs $/ \mathrm{ml}$, $9.3 \times 10^{4} \mathrm{PMP} / \mathrm{ml}, 968.87 \mathrm{EMP} / \mathrm{ml}, 244.01 \mathrm{GMP} / \mathrm{ml}, 190.57$
Tang-MP/ml and $3.8 \times 10^{3} \mathrm{MoMP} / \mathrm{ml}$; CVR: $2.2 \times 10^{6}$ total $\mathrm{MPs} / \mathrm{ml}, 9.9 \times 10^{4} \mathrm{PMP} / \mathrm{ml}, 500.23 \mathrm{EMP} / \mathrm{ml}, 172.64 \mathrm{GMP} / \mathrm{ml}$, 227.61 Tang-MP $/ \mathrm{ml}$ and $2.8 \times 10^{3} \mathrm{MoMP} / \mathrm{ml}$; and RA: $4.1 \times 10^{6}$ total $\mathrm{MPs} / \mathrm{ml}, 12.4 \times 10^{4} \mathrm{PMP} / \mathrm{ml}, 2200.6 \mathrm{EMP} / \mathrm{ml}, 1024.86$ GMP $/ \mathrm{ml}, 829.65$ Tang-MP/ml and $\left.5.1 \times 10^{3} \mathrm{MoMP} / \mathrm{ml}\right)$. Similarly, age and gender distribution did not differ among groups ( $P=0.70$ and $P=0.327$, respectively). PPP was centrifuged as previously described and supernatants were discarded and replaced with HMEC-I complete medium so as to eliminate residual plasma containing soluble mediators. Then, the volume was adjusted to obtain uniform total MPs concentration in the different pools and serial dilutions were performed according to the experimental design. Two different pools were prepared per group and assayed simultaneously. HMEC-I cells were cultured in MCDB131 medium (Sigma) supplemented with $10 \%$ foetal 
calf serum (PAA, Belgium), $100 \mu \mathrm{g} / \mathrm{ml}$ streptomycin and ampicillin (PAA), $2 \mathrm{mM}$ glutamine (Sigma), $1 \mu \mathrm{g} / \mathrm{ml}$ hydrocortisone (Sigma) and $10 \mathrm{ng} / \mathrm{ml}$ epidermal growth factor (Immunostep) in a humidified incubator with $5 \% \mathrm{CO}_{2}$ at $37^{\circ} \mathrm{C}$. Assays were performed within the second and sixth passages.

For angiogenesis assays, 96-well plates were coated with $50 \mu \mathrm{l}$ of Matrigel (BD) and left $30 \mathrm{~min}$ at $37^{\circ} \mathrm{C}$ for polymerization. Then, 50000 HMEC-I cells resuspended in $100 \mu$ l of complete medium were added to each well, followed by the addition of MPs suspensions $(50 \mu 1)$ at different concentrations by duplicate. After $16 \mathrm{~h}$ of culture, both tube formation and branching points were quantified on one focal plane in three no-overlapping fields per well (27) at 40× magnification, using a Motic AE2000 (Motic) inverted microscope equipped with a compatible digital camera (Moticam 2000, Motic).

To assay endothelial activation, HMEC-I cells were cultured in 24-well plates with MP suspensions at different concentrations for $16 \mathrm{~h}$. Then, cells were washed and stained with Fixable Viability dye e $450 \mathrm{~nm}$ (eBioscience) for $30 \mathrm{~min}$ in the dark. Next, cells were washed and stained with different antibodies: anti-VEGFR2-PE (R\&D), anti-CD144-APC (Milteny) and antiCD62E-APC (Immunostep) for 30 min at $4^{\circ} \mathrm{C}$. Finally, cells were washed again to eliminate non-binding antibodies and immediately analysed by flow cytometry.

\section{TNF $\alpha$ quantification}

Serum aliquots were stored at $-80^{\circ} \mathrm{C}$ until cytokine measurements. Tumour necrosis factor $\alpha(\mathrm{TNF} \alpha)$ serum levels were quantified using a BD OptEIA kit (BD) following the manufacturer's instructions. The detection limit was $1.95 \mathrm{pg} / \mathrm{ml}$.

\section{Statistical analysis}

Data are expressed as median (interquartile range) unless otherwise stated. Differences between MP concentrations were assessed using the Kruskal-Wallis test with Dunn-Bonferroni correction for multiple comparisons test, whereas correlations were studied using the Spearman ranks test. TNF $\alpha$ effect on MPs counts was studied by multivariate lineal regression analysis adjusted by traditional CV risk factors. MPs counts were logtransformed for normalization prior to regression analyses. Because of the high number of parameters studied, a Principal Component Analysis (PCA) was performed, including traditional CV risk factors and demographic, clinical and inflammatory parameters. The number of components retained was based on eightenvalues $(>1)$ and loadings $>0.5$ were used to identify the variables comprising a component. Principal component scores were calculated for each patient and used for multivariate regression analysis. Results from in vitro assays were analysed by one-way ANOVA with Dunnett post-hoc test. SPSS 19.0, R 3.0.3 and GraphPad Prism 5.0 for Windows were used.

\section{RESULTS}

\section{MP counts were increased in RA patients}

Circulating MPs were quantified by flow cytometry in plasma samples from 114 RA patients (Table 1), $33 \mathrm{HC}$ and 72 individuals with different traditional CV risk factors (Supplementary Table S1). The strategy used to identify MPs is presented in Figure 1. MP gate was set within 0.3 and $1.1 \mu \mathrm{m}$ using latex microbeads and PRP, with most of the detected MPs being smaller than $0.6 \mu \mathrm{m}$ (Figure 1A). Total cell-derived MPs were defined as those events within this gate and positive for VPD staining (Figure 1B). Specific MPs subsets were identified by their surface markers: $\mathrm{CD}_{4} 1^{+}$(platelet-derived MPs, PMP), CD146 ${ }^{+}$(endothelialderived MPs, EMP), CD14+ (monocyte-derived MPs, MoMP), $\mathrm{CD} 6 \mathrm{~b}^{+}$(granulocyte-derived MPs, GMP) and $\mathrm{CD}^{+}{ }^{+} \mathrm{CD} 31^{+}$ (Tang-derived MPs, Tang-MP) (Figure 1C). Gates were adjusted by the signal provided by the negative control of VPD-stained MPs.

Absolute counts of total MPs in patients and controls and that of different subsets are summarized in Figure 2. Total number of MPs was significantly increased in CVR individuals compared with HC [3.14(2.6) $\times 10^{6}$ compared with $2.10(1.23) \times 10^{6}$ $\mathrm{MPs} / \mathrm{ml}]$ and further increased in RA patients $\left[4.21(3.02) \times 10^{6}\right.$ $\mathrm{MPs} / \mathrm{ml}$. Although platelets were the main source of MPs among the analysed subsets, they did not show a significant increase in any group. However, the absolute number of MPs derived from endothelial cells, granulocytes and Tang lymphocytes were significantly increased as was the number of total MPs in RA patients. Accordingly, the frequency of these MP subsets out of the total MPs was also increased in RA patients compared with HC (EMP: 0.05(0.10) compared with $0.02(0.067) \%, P=0.029$; GMP: 0.02(0.03) compared with $0.01(0.00) \%, P=0.001$; TangMP: 8.16(11.70) compared with $1.20(6.76) \%, P<0.0001)$. Conversely, no differences were registered in the different MP subsets between the CVR group and HC. Therefore, RA patients exhibit not only a quantitative increase but also an altered MP profile.

\section{MP profile was associated with traditional CV risk factors and disease-specific parameters}

Next, we wondered whether traditional $\mathrm{CV}$ risk factors and/or disease-specific parameters could account for the MP alterations detected in RA patients. Notably, total MPs number was positively associated with some traditional $\mathrm{CV}$ risk factors in both RA and CVR patients. Specifically, similar significant correlations were detected with triglycerides (RA: $r=0.390$, $P<0.0002$; CVR: $r=0.358, P=0.012$ ), total/high-density lipoprotein (HDL)-cholesterol ratio (RA: $r=0.319, P=0.004$; CVR: $r=0.298, P=0.040$ ) and body mass index (BMI) (RA: $r=0.232, P=0.021$; CVR: $r=0.304, P=0.022$ ). Also, the number of traditional $\mathrm{CV}$ risk factors correlated with total MP counts $(r=0.221, P=0.030)$. However, none of these associations were observed with any specific MP subset.

Nevertheless, the striking increase in the absolute number and the differences in MP composition detected in RA patients could not be explained by the presence of traditional CVR factors. Therefore, cellular damage and/or activation related to disease specific parameters may play a role. In this sense, interesting associations were found: EMP counts correlated positively with disease duration $(r=0.285, P=0.005)$; GMP with DAS28 $(r=0.271, P=0.032)$, erythrocyte sedimentation rate (ESR) $(r=0.233, P=0.022)$ and age at diagnosis $(r=0.233$, $P=0.021)$; Tang-MP with DAS28 $(r=0.275, P=0.007)$, tender 
A.

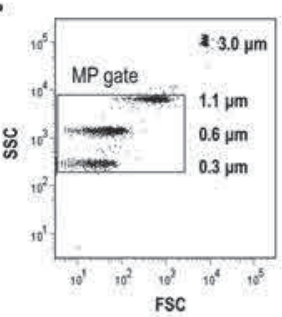

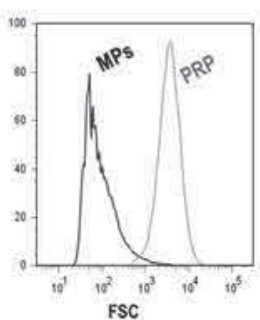

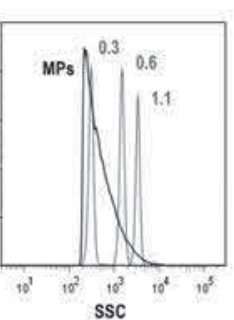

B.

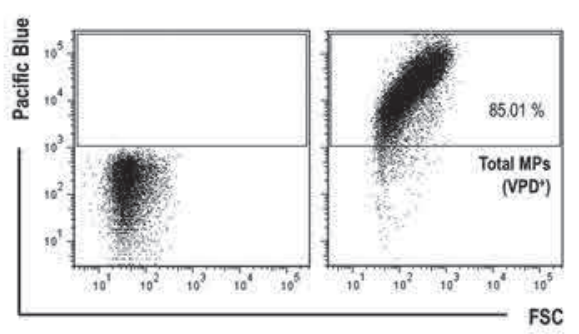

C.

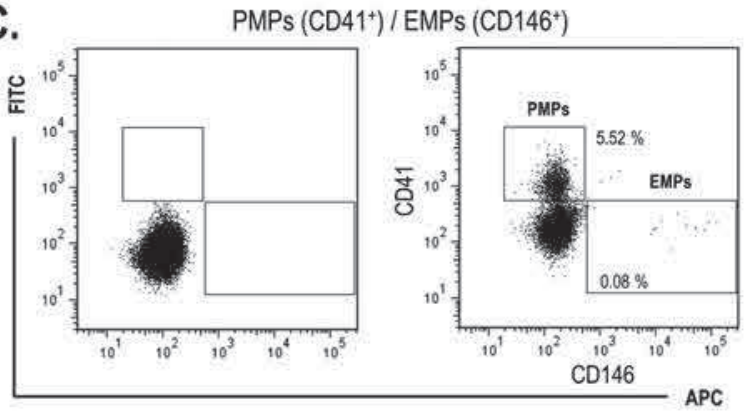

$\operatorname{MoMPs}\left(\mathrm{CD} 14^{+}\right) / \mathrm{GMP}\left(\mathrm{CD} 66 \mathrm{~b}^{+}\right)$

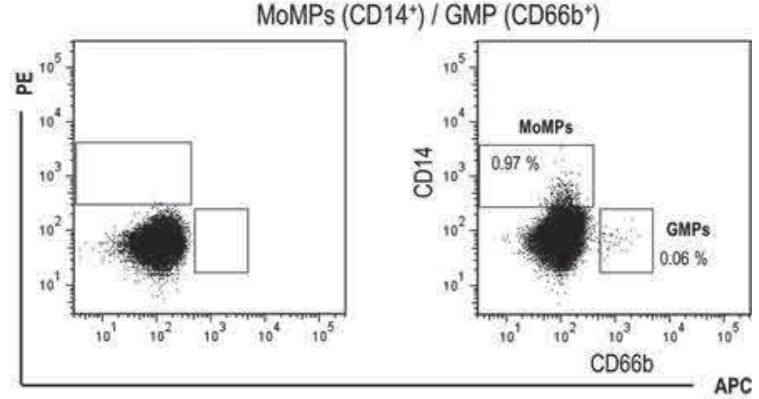

Tang-MPs $\left(\mathrm{CD}^{+} \mathrm{CD}^{-1^{+}}\right)$
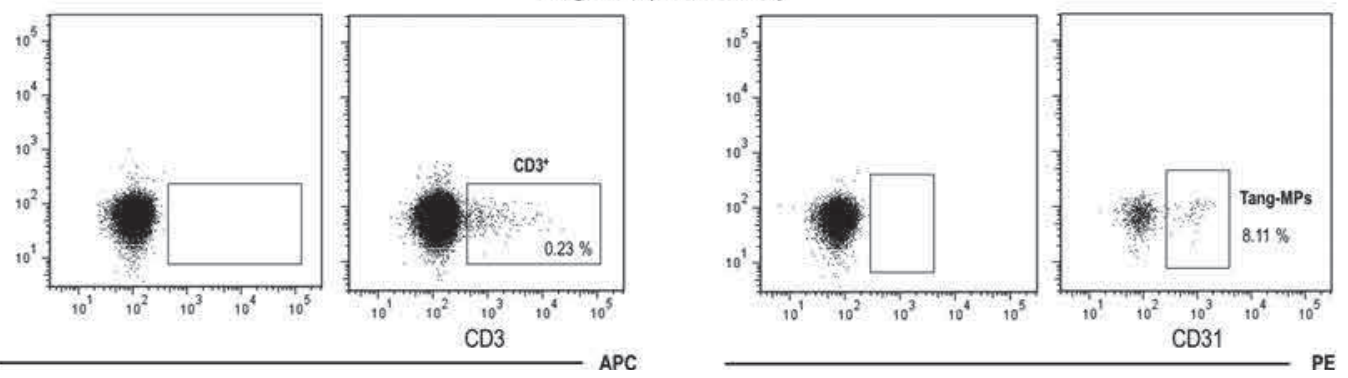

Figure 1 Gating strategy for MP analysis

(A) Latex beads were used to calibrate FSC and SSC logarithmic gain and to design MP gate. Analysis of MP suspension revealed that most MPs had this size. PRP sample was prepared to confirm MP gate. (B) Total MPs were defined as those events VPD ${ }^{+}$. Threshold was adjusted with an unstained MP suspension. (C) Gating strategy for PMPs (CD41 ${ }^{+}$MPs), EMPs (CD146 ${ }^{+}$MPs), GMPs (CD66 ${ }^{+}$MPs), MoMPs (CD14 $\left.{ }^{+} \mathrm{MP}\right)$ and Tang-MPs (CD3 ${ }^{+}$MPs were first gated and evaluated by their $\mathrm{CD}_{3} 1^{+}$expression and those $\mathrm{CD} 3^{+} \mathrm{CD} 31^{+}$double-positive were defined as Tang-MPs).

$(r=0.229, P=0.026)$ and swollen joint counts $(r=0.306$, $P=0.003)$ and MoMP with RF titre $(r=0.240, P=0.041)$. Interestingly, patients on tocilizumab treatment exhibited lower Tang-MPs $(P=0.050)$ and GMPs $(P=0.011)$, whereas methotrexate usage was related to decreased Tang-MPs counts $(P=0.033)$, probably associated to the lower DAS28 $(P<0.001$ and $P=0.008$, respectively) found in these patients. Therapies used in the CVR did not result in different MPs counts in any of the subsets analysed.

All these results indicated that a large number of parameters, including traditional $\mathrm{CV}$ risk and disease specific factors, accounted for total and specific MP subsets in RA patients. Therefore, we employed a PCA to reduce this number into a small set of components that could explain most of the variance of the MP counts. This method also provides an integrative approach for the different factors included, avoiding potential collinearity bias and multiple testing concerns. PCA was conducted with the parameters summarized in Table 2 and all of them exhibited communalities higher than 0.5. The Kaiser-MeyerOlkin test provide a good adequacy of the data $(0.687)$ as the Bartlett test of sphericity $\left(P=10^{-49}\right)$ did. Results of the PCA provided four components with eigenvalues $>1$, which were interpreted based on the loadings relating the variable to the component. Thus, loadings higher than 0.5 were used to identify the variables that define each component. As seen in Table 2, disease-specific parameters loaded on the first component ('rheumatic-related'), whereas traditional CV risk factors loaded on the second component ('traditional CV-related'), only disease duration loaded on the third component ('duration-related') as ESR did on the fourth ('inflammation-related'). This model explained $69.0 \%$ of the total variance.

Finally, we analysed whether principal components were associated to the different MP subsets by multiple regression analysis (Table 3), being each MP subset adjusted for the four components. Interestingly, we found that traditional CVR factors (component 2) can predict total MPs numbers, whereas the counts of specific 

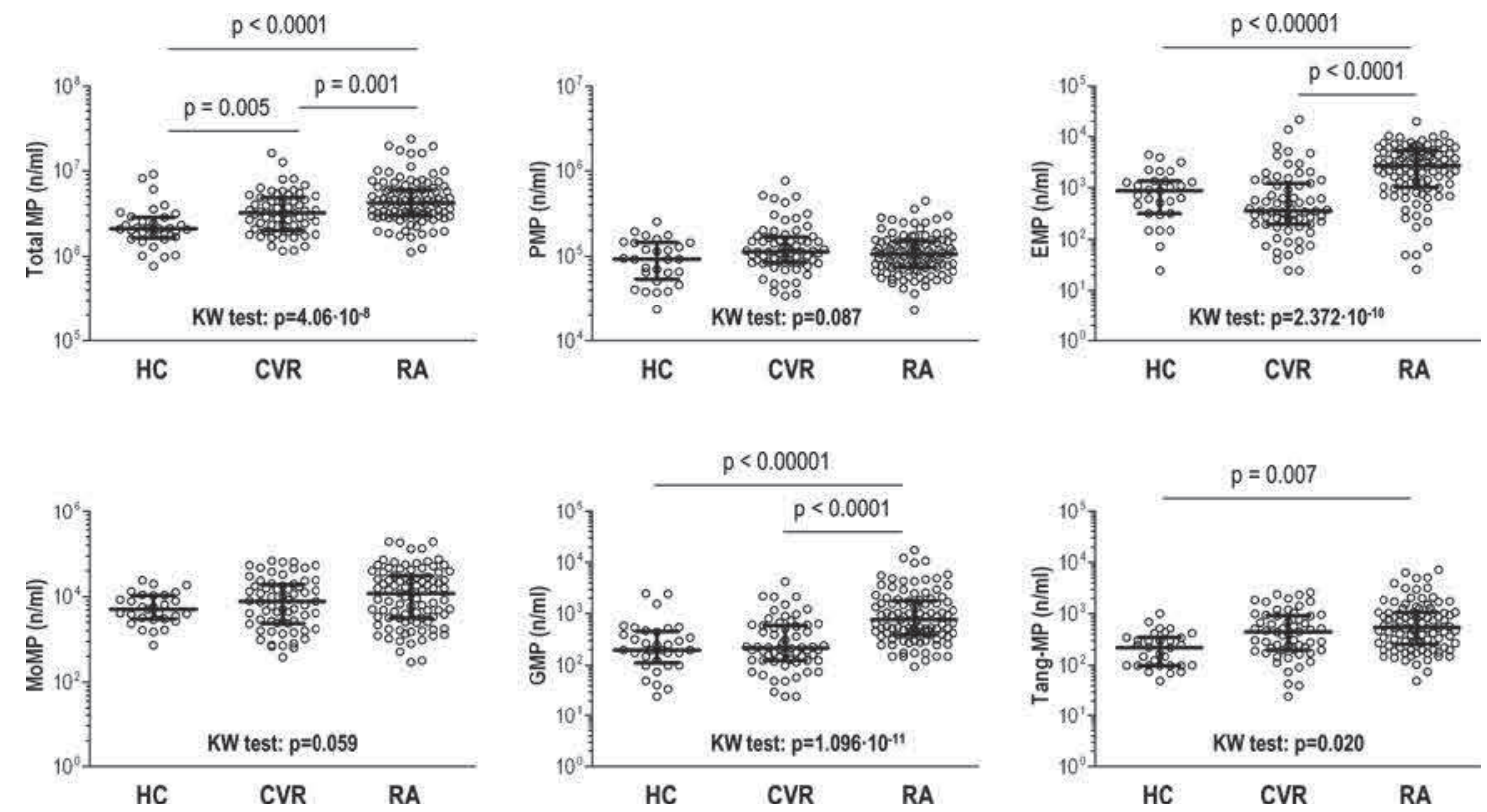

Figure 2 Total and specific MP subsets in patients and controls

Absolute number of total MPs and PMPs, EMPs, MoMPs, GMPs and Tang-MPs was analysed in 114 RA patients, 72 individuals with traditional CVR factors and $33 \mathrm{HC}$. Horizontal lines represent median and interquartile range. Differences were assessed by Kruskal-Wallis with Dunn-Bonferroni multiple comparison tests. Kruskal-Wallis $P$ value for each subset is indicated at the bottom. Only significant $P$ values from multiple comparisons tests are indicated.

\section{Table 2 Component loadings from PCA}

Variables included in the analysis and their corresponding loading on each component are shown. Variables were assigned to each component based on loadings $>0.5$. Loadings in bold indicate the component on a variable loaded the highest.

\begin{tabular}{|c|c|c|c|c|}
\hline Disease duration (years) & 0.123 & 0.330 & 0.580 & -0.470 \\
\hline Tender joints count & 0.774 & -0.356 & -0.280 & 0.014 \\
\hline Swollen joints count & 0.701 & -0.330 & -0.255 & -0.019 \\
\hline Health Assessment Questionaire (0-3) & 0.706 & 0.140 & 0.031 & -0.203 \\
\hline Global patient assessment (1-100) & 0.861 & -0.002 & 0.037 & -0.107 \\
\hline $\operatorname{ESR}(\mathrm{mm} / \mathrm{h})$ & 0.262 & 0.172 & 0.574 & 0.704 \\
\hline Disease activity (DAS28) & 0.844 & -0.104 & 0.135 & 0.360 \\
\hline BMI $\left(\mathrm{kg} / \mathrm{m}^{2}\right)$ & 0.293 & 0.786 & -0.126 & 0.055 \\
\hline
\end{tabular}

MP subsets are only explained by disease-specific parameters (components 1 and 3). These observations support our previous findings.

\section{TNF $\alpha$ levels correlated with Tang-MPs unless traditional CV risk factors were present}

Elevated production of TNF $\alpha$, a cytokine involved in RA pathogenesis, has been related to cell activation, apoptosis and endothelial damage. Therefore, to evaluate whether it could play a role in MP release, serum levels of this cytokine were quantified in RA patients and $\mathrm{HC}$.
In spite of the increased levels of TNF $\alpha$ present in RA patients [8.42(9.12) compared with 5.35(4.25) $\mathrm{pg} / \mathrm{ml}, P=0.001]$, they were unrelated to the total MP number $(r=0.037, P=0.730)$. Further analysis of MP subsets, showed Tang-MP counts were slightly associated to TNF $\alpha(r=0.171, P=0.097)$, but this correlation becomes relevant in RA patients without any traditional $\mathrm{CV}$ risk factor $(n=24, r=0.669, P<0.0001)$. Moreover, this association was also apparent, although at a lower level, in patients with less than two traditional CV risk factors $(n=51, r=0.459$, $P=0.001)$, and in those with less than three factors $(n=73$, $r=0.244, P=0.038$ ), indicating that the higher number of traditional $\mathrm{CV}$ risk factors, the lower TNF $\alpha$ contribution to MP 
Table 3 Multivariate regression analyses of MP subsets in RA patients

Multivariate regression analyses of MP subsets (as dependent variables) and the four components obtained by PCA components (as predictors) associated with specific disease variables: rheumatic-related (Rhe-rel), traditional CV-related (tCV-rel), disease duration-related (Dur-rel) and inflammation-related (Infl-rel). Results are expressed as $\beta$ coefficient and ( $P$ value) for each PCA component. Significant coefficients are highlighted in bold.

\begin{tabular}{lrrrrrr}
\hline Variable & \multicolumn{1}{l}{ Total MPs } & \multicolumn{1}{l}{ PMPs } & \multicolumn{1}{l}{ EMPs } & \multicolumn{1}{l}{ GMP } & \multicolumn{1}{c}{ Tang-MPs } \\
\hline C1 (Rhe-rel) & \multicolumn{1}{c}{$-0.085(0.387)$} & $-0.007(0.948)$ & $-0.131(0.290)$ & $\mathbf{0 . 2 9 6}(\mathbf{0 . 0 1 4})$ & $\mathbf{0 . 3 1 9}(\mathbf{0 . 0 1 0})$ & $0.209(0.835)$ \\
C2 (tCV-rel) & $\mathbf{0 . 2 9 0}(\mathbf{0 . 0 0 4})$ & $0.100(0.331)$ & $0.039(0.743)$ & $-0.107(0.350)$ & $-0.008(0.944)$ & $-0.105(0.389)$ \\
C3 (Dur-rel) & $-0.014(0.889)$ & $-0.017(0.869)$ & $\mathbf{0 . 3 2 9}(\mathbf{0 . 0 0 8})$ & $-0.053(0.650)$ & $0.073(0.540)$ & $-0.173(0.167)$ \\
C4 (Infl-rel) & $0.058(0.551)$ & $0.061(0.548)$ & $-0.119(0.312)$ & $0.091(0.427)$ & $0.118(0.316)$ & $0.164(0.186)$
\end{tabular}

release. Actually, analysing all RA patients in a multivariate regression model including traditional $\mathrm{CV}$ risk factors, TNF $\alpha$ was associated with Tang-MP counts $(r=0.259, P=0.012)$. No association with other MP subsets was found.

\section{MPs from RA patients promoted endothelial disturbance in vitro}

Finally, since MPs have been linked to CV risk and endothelial activation, we performed in vitro experiments to evaluate whether circulating MPs isolated from HC, RA patients or individuals with traditional CVR factors could affect angiogenic tube formation and endothelial activation in HMEC-I cells.

Angiogenesis assays on Matrigel were conducted after adding HC-, CVR- or RA-MP pools at different concentrations (0.5$8 \times 10^{6} \mathrm{MP} / \mathrm{ml}$ ), selected according to the range of total MP counts in controls (Figure 3A). Results showed that the number of both branching points and tubes were dose-dependently inhibited by RA-MPs, whereas no effect was seen with HC- or CVR-MPs (Figure 3B). Interestingly, MPs from RA patients exhibited an anti-angiogenic effect at $1 \times 10^{6} \mathrm{MP} / \mathrm{ml}$, a lower concentration than they are usually found in plasma.

Additionally, MP-mediated activation of endothelial cells was estimated analysing by flow cytometry different endothelialspecific markers, as well as cell viability, in HMEC-I cells cultured in the presence of the different MP pools (Figure 3C). No cytotoxic effect was seen under any of the conditions tested, thus excluding that viability could affect endothelial functionality. However, we observed that RA-, but not HC- or CVR-MPs, increased the expression of CD62E, CD144 and VEGFR2 (all $P<0.050$ ), thus suggesting the promotion of an activated endothelial status.

Finally, to assess whether these findings could be attributed to a specific cell-derived MP subset, the amount of each MP subset present in the cultures was compared with the effects found on angiogenic assays. Figure 4 shows that the detrimental effect observed with total RA MPs was also detected when the different subsets were analysed, but it seems to be different depending on their cellular origin. Analysing the effects at physiological levels (median value in $\mathrm{HC}$ ), striking differences between RA and HC were observed with MoMPs and PMPs but no with GMPs and Tang-MPs, thus suggesting that the deleterious effect of Tangand GMP- RA MPs could be due to the increased proportion within the total MP count, whereas MoMPs and PMPs from RA patients could have a detrimental effect by themselves.
Therefore, MPs from RA patients are able to disturb in vitro endothelial functionality dose-dependently, maybe due to an endothelial activation, whereas HC- and CVR-MPs did not promote this effect, even at greater concentrations. These results are a proof of concept that supports functional qualitative and quantitative effects associated to a skewed composition of RA MPs.

\section{DISCUSSION}

The study reported here shows relevant differences in the number and composition of circulating MPs in RA patients compared with $\mathrm{HC}$ and individuals with traditional $\mathrm{CV}$ risk factors. Additionally, the main finding is that this altered MP pool is the result of disease features as well as traditional $\mathrm{CV}$ risk factors, as was supported using a PCA approach. This distinct profile could underlie the detrimental effects exhibited by RA-MPs in endothelial cells assays, presumably by promoting an endothelial activation status. The results herein presented support the use of MPs as biomarkers of endothelial damage in RA patients, with potential use for clinicians in decision making and $\mathrm{CV}$ risk stratification.

In line with our results, other studies performed with RA patients showed increased MP counts, total or specific from different cell subsets and associated with some clinical features [27-29]. However, evidence is limited and results are heterogeneous and even contradictory, probably because of the different methodologies used. We have developed a MP total labelling strategy so as to (i) identify virtually all MPs and not only those derived from apoptosis and (ii) avoid the technical drawbacks associated with annexin V staining. Recent evidence suggests the relevance of annexin V-negative MPs in many conditions. Actually, Nielsen et al. reported that in Systemic Lupus Erythematosus patients only annexin V-negative MPs were increased and associated with clinical parameters [19], whereas other authors have reported that most MPs did not express annexin V $[17,18,30]$, so limiting the study to this subset could bias the conclusions. On the other hand, freezing steps and several other factors are thought to affect the annexin $\mathrm{V}$ binding-fraction [26,31-33], thus making the comparison between different studies difficult and emphasizing the need for alternative protocols. In this sense, different reagents have been published [18,34-37] to overcome annexin $\mathrm{V}$ disadvantages. 
A.

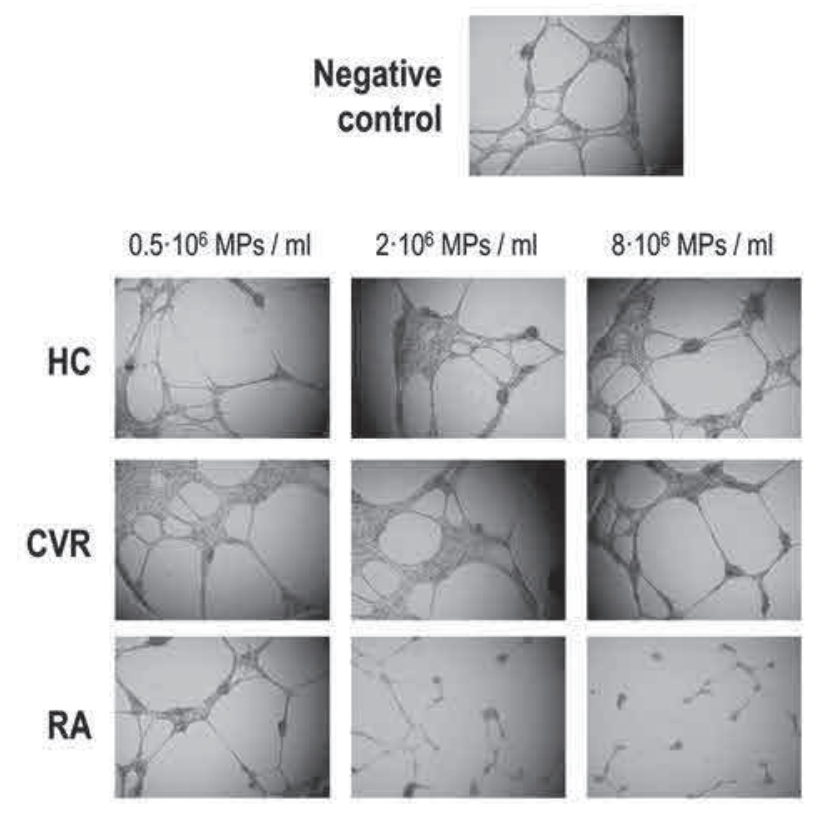

B. $\square$ NC $\square$ HC-MPs $\square$ CVR-MPs $\square$ RA-MPs
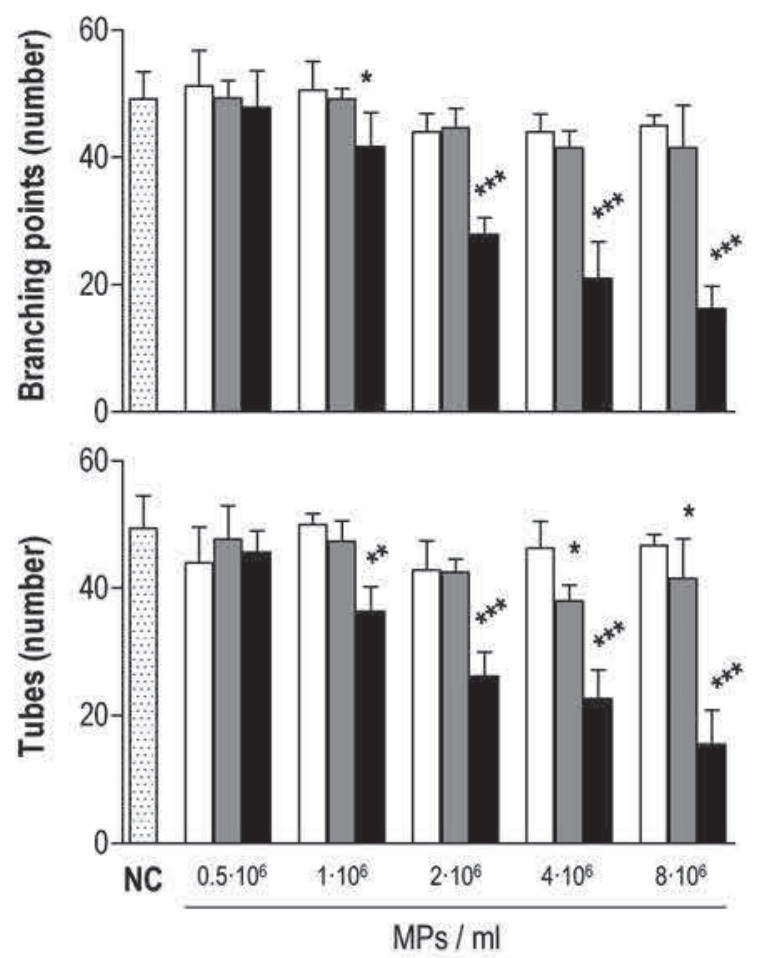

C. $\square$ NC

CVR-MPs

RA-MPs
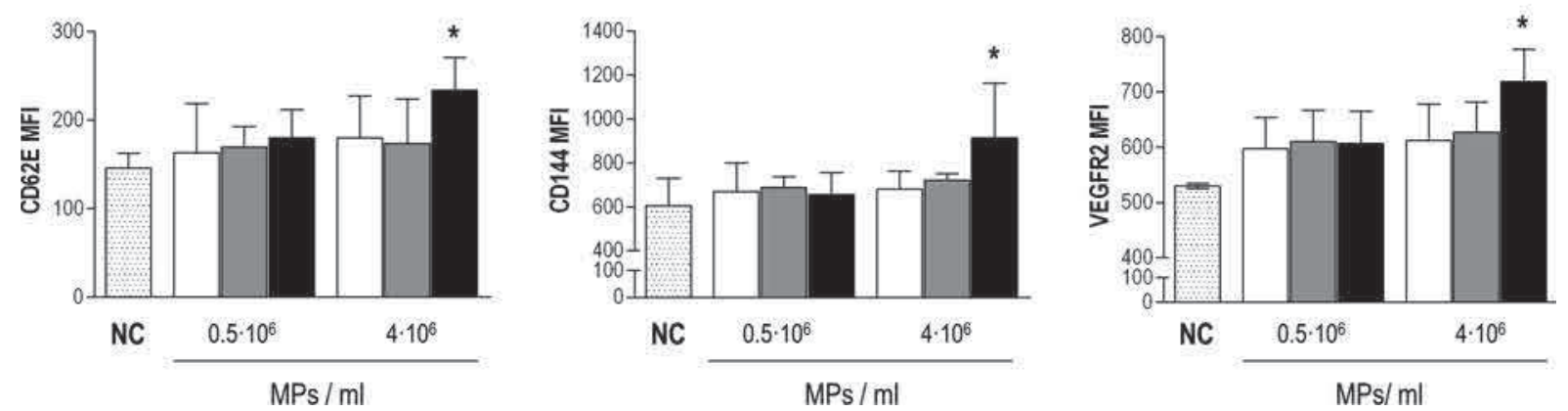

Figure 3 In vitro effects of MPs isolated from patients and controls

HMEC-I cells were cultured alone (negative control, NC) or in the presence of MP pools at different concentrations isolated from RA patients, individuals with traditional CVR factors or HC. (A) Representative microphotographs $(\times 40)$ of HMEC-I cells cultured on Matrigel coated plates to perform angiogenic assays. (B) Branching points and tubes numbers identified in different cultures $(n=8)$. (C) Flow cytometry analysis of CD62E, CD144 and VEGFR2 expression on HMEC-I cells cultured in the presence of the different MP pools $(n=4)$. Bars represent means \pm S.D. and differences between each treatment and the negative control were assessed with one-way ANOVA and Dunnett post-hoc test.

Because of their role in inflammation, angiogenesis and vascular reactivity, MPs have been extensively studied in RA and rheumatic diseases [1]. However, this is the first study in which a PCA was used as an integrative tool to analyse MP counts, thus avoiding multiple-testing concerns and supporting previous results. This work clearly indicates that total MP counts can be explained by traditional $\mathrm{CV}$ risk factors in individuals at risk (RA and CVR subjects), but RA patients exhibited a profile of increased MP subsets that is only explained by disease-specific factors. Results from CVR individuals as positive CV-risk control allows us to confirm that MP disturbances in RA are specific for the disease itself and independent of comorbidities. Additionally, although PCA component scores are independent in the whole RA group, rheumatic- and traditional CV-related components were positively correlated in the patients who had a history of $\mathrm{CV}$ events $(r=0.602, P=0.008 ; n=18)$ but not in the $\mathrm{CV}$-free group $(r=0.032, P=0.759)$, revealing the relationship between these two features. These results are in line with recent evidence about the interplay of traditional CV risk factors and disease parameters in RA [38,39]. Moreover, disease-specific factors 
Total MPs

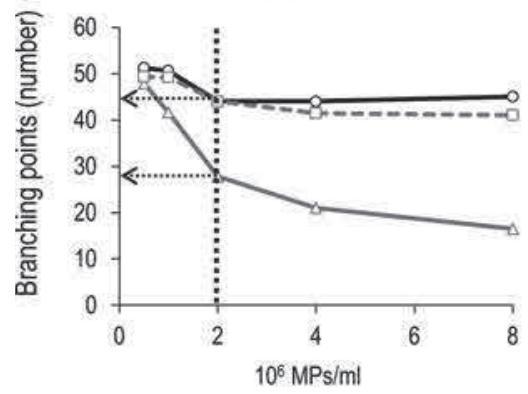

EMPS

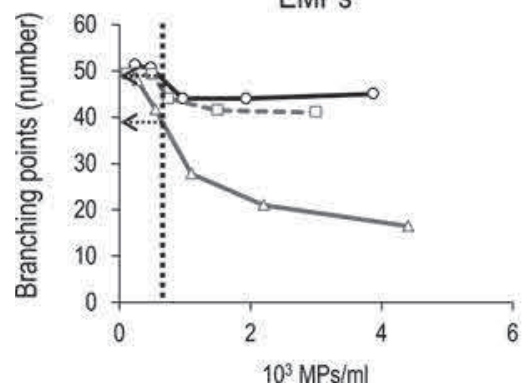

Tang-MPs
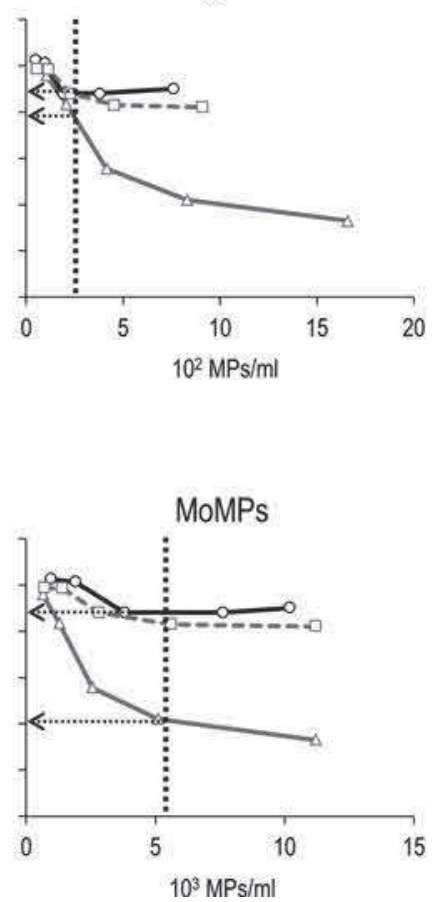

GMPs

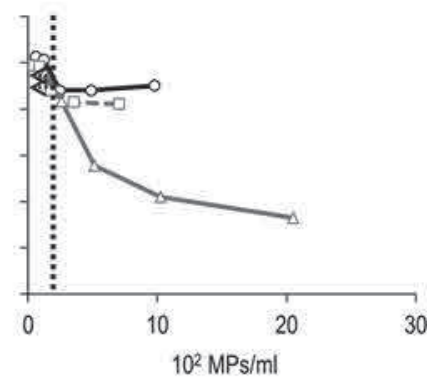

PMPS

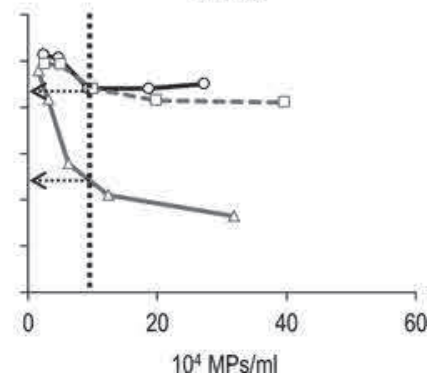

Figure 4 In vitro effects analysed according to different MP subsets

The in vitro effect of MPs (measured as number of branching points) was analysed separately according to the different subsets studied. RA MPs (triangles, grey full line) exhibited greater detrimental effect on branching point numbers than those from HC (circles, black line) and CVR (squares, broken grey line) even at the same concentration, although differences were observed when PMPs and MoMPs were compared with GMPs and Tang-MPs. Vertical dotted line represents the median value found in $\mathrm{HC}$.

associated with MP subsets in the present study (disease duration, DAS28 and age at diagnosis) have been associated with CV disease in RA [38,40,41], thereby supporting the relevance of MPs as biomarkers of endothelial activation and damage in RA patients.

Another interesting finding of this work is the role played by MPs derived from Tang cells, a recently-discovered T-cell subset that enhance endothelial repair through cooperating with endothelial progenitor cells [42]. Although no differences in the frequency of MPs derived from T-lymphocytes were detected, both frequency and absolute number of Tang-MPs were increased in RA patients. Interestingly, this increased Tang-MP formation could account for the decreased Tang cell counts previously reported in RA [21]. Moreover, our research revealed a DAS28-dependent Tang-MP shedding, thus linking DAS28 with impaired endothelial repair. Actually, the disease parameters positively associated with Tang-MP in this work were the same as has been found negatively associated with Tang frequency [21]. Consequently, Tang-MPs could be considered as a surrogate biomarker of endothelial damage and vascular repair failure. Furthermore, the association between $\mathrm{TNF} \alpha$, a proapoptotic cytokine increased in RA, and Tang-MPs reinforces this hypothesis and the link between disease-specific parameters and MP release. Again, the finding that the presence of traditional $\mathrm{CV}$ risk factors disturbs this association confirms the interplay between traditional $\mathrm{CV}$ risk factors and disease features.

In spite of the striking increase in total MPs in patients, there were not differences compared with controls in the PMP counts, suggesting that the RA-specific MP profile may not simply be due to a general MP increase, but rather specific mechanisms targeting different cell populations may be implicated. Accordingly, no associations were detected between PMPs and PCA components, whereas EMPs, GMPs and Tang-MPs correlated positively with disease-related parameters. Another plausible explanation is that therapies would interfere with platelet function, however, no effect of the concomitant medications was observed, neither when untreated patients (allowed to use NSAIDs) were analysed, thus excluding a confounding effect of drug usage on platelet activation. Hence, we could attribute these results to the analysis performed in our study. In fact, increased PMP counts in RA were observed when annexin- $\mathrm{V}$ binding was used $[28,29]$, however, when alternative procedures were performed, opposed results were achieved $[19,29]$. This lead us to hypothesize that the total labelling protocol performed in this work could mask the differences in Annexin V-positive PMPs due to an elevated number of negative-events. Therefore, although possible platelet activation during PPP isolation cannot be ruled out, our functional assays indicated that the in vitro detrimental effects of MPs from RA patients depend on qualitative alterations in PMPs rather 
than differences in absolute counts, contrary to was observed with Tang- or GMPs (Figure 4).

The fact that the RA MP profile can only be explained by disease-specific features leads us to think that these MPs may have a role in RA pathogenesis. Recent studies analysing the MP proteome support this idea [43]. Accordingly, differential 'MP signature' was found in synovial fluid from RA patients compared with other arthritidies [44]. Thus, in this pathological situation, MPs could be acting in a vicious circle: disease-related cell injury could generate a RA-specific MP pool which in turn might worsen specific clinical features, as might be damaging vascular endothelium, with subsequent increase in $\mathrm{CV}$ risk. Accordingly, MPs from RA patients have been reported to be able to modulate chemokines and cytokines from synoviocytes [45], thus probably amplifying inflammatory responses.

Finally, the existence of a RA-specific MP profile was supported by our in vitro assays, since they revealed that effects on endothelial cells depend on the MP pool rather than the concentration (even within physiological concentrations). Specifically, RA-MPs were able to inhibit HMEC-I Matrigel tube formation in a dose-dependent manner, whereas MPs derived from $\mathrm{HC}$ and CVR individuals failed to exhibit similar results. This detrimental effect may be due to the promotion of endothelial activation, as was indicated by flow cytometry analysis of endothelial markers. In fact, endothelial activation has been associated with impaired endothelial function in a variety of conditions [46], including RA [47]. A role for MPs in CV disease and endothelial function has been previously reported $[48,49]$, but this is the first study where MPs isolated from RA patients have been assayed. Despite providing limited evidence, these results could support the role of MPs as active players in RA pathogenesis, proving worthy of further research.

However, it should be noted that not all MPs are proatherogenic. Actually, some groups revealed anticoagulant and protective effects of some MP subsets [50-52], in contrast with the procoagulant and deleterious results reported by others $[10,27,45,48,53]$. Interestingly, these diverse effects could be attributed to the exposure of different mediators, such as activated protein $\mathrm{C}$, tissue factor or von Willebrand factor among MP subsets. Although these effects cannot be excluded with the actual data, our results from in vitro assays point to a pathogenic role of MPs in RA patients.

Some remarks about the current study should be made. First, despite covering the same age range, $\mathrm{HC}$ were younger that RA and CVR patients. However, no associations between age and MP counts were detected in any group. Additionally, age was included in the PCA in order to correct for potential differences. On the other hand, the lack of a standardized protocol to determine cellderived MPs is the main limitation in the field of MPs. The fact that we have developed a new protocol enabling the determination of the total MPs could make the comparison of our results with other studies difficult, since usually only apoptosis-derived MPs were analysed. However, this is a common problem in the field, and a balance between innovative methods and potential results should be considered. Nevertheless, our findings are relatively similar to others obtained by different methods. Finally, although our data did not allow direct determination of the detrimental effects of each specific MP subset, the in vitro results suggest differences between them. Further studies are needed to confirm this hypothesis, however, MPs separation procedures from plasma have not been implemented yet. Furthermore, circulating MPs are present in vivo as a (heterogeneous) group, so 'individual' in vitro effects of a single population need to be considered with caution. In conclusion, the findings of the present study reveal that RA patients exhibited not only increased MP counts but also a qualitatively altered MP profile that is associated with diseasespecific and CV risk factors. Moreover, this MP profile could be able to disturb vascular endothelium. In addition, increased Tang-MPs, probably associated with the DAS28-dependent Tang decrease, could have a role in endothelial repair failure in these patients, thereby supporting the use of both Tang and Tang-MPs as biomarkers of endothelial repair failure.

\section{CLINICAL PERSPECTIVES}

- It is known that the number of cell-derived microparticles (MPs) is associated with endothelial dysfunction and impaired vascular repair.

- RA patients exhibit a specific MP profile that is associated with both disease-specific features and traditional CVR factors. This specific profile could underlie the detrimental effects on endothelial cells in vitro, presumably by promoting endothelial activation.

- MPs could be considered as biomarkers of endothelial damage in RA patients, with potential use for clinicians in decision making and $\mathrm{CV}$ risk stratification.

\section{AUTHOR CONTRIBUTION}

Javier Rodríguez-Carrio performed most of the experimental procedures, carried out statistical analyses and drafted the manuscript. Patricia López and Santiago Carro-Esteban performed some experimental procedures. Mercedes Alperi-López, Sara Alonso-Castro and Francisco Ballina-García were in charge of patients' recruitment and clinical data collection. Ana Suárez conceived the study, designed the protocols and drafted and edited the manuscript. All authors read and approved the final version of the manuscript.

\section{ACKNOWLEDGEMENTS}

We thank Ms Isabel Crespo (IDIBAPS, Barcelona) for her technical advice and clinical staff from primary care health centre Centro de Salud Sariego (Pola de Siero, Asturias) for blood samples management and clinical data collection.

\section{FUNDING}

This work was supported by the European Union FEDER funds, Fondo de Investigación Sanitaria (FIS) [grant number PI12/00523]; the Ayudas de Cofinanciación-FICYT [grant number COF13-12]; and a FPU fellowship from the Ministerio de Educación (Spain) (to J.R.C.). 


\section{REFERENCES}

1 Beyer, C. and Pisetsky, D. S. (2010) The role of microparticles in the pathogenesis of rheumatic diseases. Nat. Rev. Rheumatol. 6, 21-29 CrossRef PubMed

2 Burger, D., Schock, S., Thompson, C. S., Montezano, A. C., Hakim, A. M. and Touyz, R. M. (2013) Microparticles: biomarkers and beyond. Clin. Sci. 124, 423-441 CrossRef PubMed

3 Hugel, B., Martinez, M. C., Kunzelmann, C. and Freyssinet, J. M. (2005) Membrane microparticles: two sides of the coin. Physiology 20, 22-27 CrossRef PubMed

4 Guiducci, S., Distler, J. H., Jungel, A., Huscher, D., Huber, L. C., Michel, B. A., Gay, R. E., Pisetsky, D. S., Gay, S., Matucci-Cerinic, M. and Distler, O. (2008) The relationship between plasma microparticles and disease manifestations in patients with systemic sclerosis. Arthritis Rheum. 58, 2845-2853 CrossRef PubMed

5 Barteneva, N. S., Fasler-Kan, E., Bernimoulin, M., Stern, J. N., Ponomarev, E. D., Duckett, L. and Vorobjev, I. A. (2013) Circulating microparticles: square the circle. BMC Cell Biol. 14, 23 CrossRef PubMed

6 Thery, C., Ostrowski, M. and Segura, E. (2009) Membrane vesicles as conveyors of immune responses. Nat. Rev. Immunol. 9, 581-593 CrossRef PubMed

7 Amabile, N., Heiss, C., Real, W. M., Minasi, P., McGlothlin, D., Rame, E. J., Grossman, W., De, M. T. and Yeghiazarians, Y. (2008) Circulating endothelial microparticle levels predict hemodynamic severity of pulmonary hypertension. Am. J. Respir. Crit. Care Med. 177, 1268-1275 CrossRef PubMed

8 Rautou, P. E., Vion, A. C., Amabile, N., Chironi, G., Simon, A., Tedgui, A. and Boulanger, C. M. (2011) Microparticles, vascular function, and atherothrombosis. Circ. Res. 109, 593-606 CrossRef PubMed

9 Lee, Y. J., Jy, W., Horstman, L. L., Janania, J., Reyes, Y., Kelley, R. E. and Ahn, Y. S. (1993) Elevated platelet microparticles in transient ischemic attacks, lacunar infarcts, and multiinfarct dementias. Thromb. Res. 72, 295-304 CrossRef PubMed

10 Mesri, M. and Altieri, D. C. (1999) Leukocyte microparticles stimulate endothelial cell cytokine release and tissue factor induction in a JNK1 signaling pathway. J. Biol. Chem. 274, 23111-23118 CrossRef PubMed

11 Barry, O. P. and FitzGerald, G. A. (1999) Mechanisms of cellular activation by platelet microparticles. Thromb. Haemost. $\mathbf{8 2}$, 794-800 PubMed

12 Jy, W., Mao, W. W., Horstman, L., Tao, J. and Ahn, Y. S. (1995) Platelet microparticles bind, activate and aggregate neutrophils in vitro. Blood Cells Mol. Dis. 21, 217-231 CrossRef PubMed

13 Kambas, K., Chrysanthopoulou, A., Vassilopoulos, D., Apostolidou, E., Skendros, P., Girod, A., Arelaki, S., Froudarakis, M., Nakopoulou, L., Giatromanolaki, A. et al. (2013) Tissue factor expression in neutrophil extracellular traps and neutrophil derived microparticles in antineutrophil cytoplasmic antibody associated vasculitis may promote thromboinflammation and the thrombophilic state associated with the disease. Ann. Rheum. Dis. 73, 1854-1863 CrossRef PubMed

14 Gonzalez-Gay, M. A., Gonzalez-Juanatey, C., Lopez-Diaz, M. J., Pineiro, A., Garcia-Porrua, C., Miranda-Filloy, J. A., Ollier, W. E., Martin, J. and Llorca, J. (2007) HLA-DRB1 and persistent chronic inflammation contribute to cardiovascular events and cardiovascular mortality in patients with rheumatoid arthritis. Arthritis Rheum. 57, 125-132 CrossRef PubMed

15 Sattar, N., McCarey, D. W., Capell, H. and McInnes, I. B. (2003) Explaining how "high-grade" systemic inflammation accelerates vascular risk in rheumatoid arthritis. Circulation $\mathbf{1 0 8}$ 2957-2963 CrossRef PubMed
16 Dey-Hazra, E., Hertel, B., Kirsch, T., Woywodt, A., Lovric, S., Haller, H., Haubitz, M. and Erdbruegger, U. (2010) Detection of circulating microparticles by flow cytometry: influence of centrifugation, filtration of buffer, and freezing. Vasc. Health Risk Manag. 6, 1125-1133 PubMed

17 Connor, D. E., Exner, T., Ma, D. D. and Joseph, J. E. (2010) The majority of circulating platelet-derived microparticles fail to bind annexin V, lack phospholipid-dependent procoagulant activity and demonstrate greater expression of glycoprotein lb. Thromb. Haemost. 103, 1044-1052 CrossRef PubMed

18 Ullal, A. J., Pisetsky, D. S. and Reich, III, C. F. (2010) Use of SYTO 13, a fluorescent dye binding nucleic acids, for the detection of microparticles in in vitro systems. Cytometry A 77, 294-301 PubMed

19 Nielsen, C. T., Ostergaard, O., Johnsen, C., Jacobsen, S. and Heegaard, N. H. (2011) Distinct features of circulating microparticles and their relationship to clinical manifestations in systemic lupus erythematosus. Arthritis Rheum. 63, 3067-3077 CrossRef PubMed

20 Enjeti, A. K., Lincz, L. F. and Seldon, M. (2007) Detection and measurement of microparticles: an evolving research tool for vascular biology. Semin. Thromb. Hemost. 33, 771-779 CrossRef PubMed

21 Rodriguez-Carrio, J., Alperi-Lopez, M., Lopez, P., Alonso-Castro, S., Ballina-Garcia, F. J. and Suarez, A. (2014) Angiogenic T cells are decreased in rheumatoid arthritis patients. Ann. Rheum. Dis., doi: 10.1136/annrheumdis-2013-204250

22 Gonzalez, A., Maradit, K. H., Crowson, C. S., Ballman, K. V., Roger, V. L., Jacobsen, S. J., O'Fallon, W. M. and Gabriel, S. E. (2008) Do cardiovascular risk factors confer the same risk for cardiovascular outcomes in rheumatoid arthritis patients as in non-rheumatoid arthritis patients? Ann. Rheum. Dis. 67, 64-69 CrossRef

23 Rodriguez-Rodriguez, L., Gonzalez-Juanatey, C., Palomino-Morales, R., Vazquez-Rodriguez, T. R., Miranda-Filloy, J. A., Fernandez-Gutierrez, B., Llorca, J., Martin, J. and Gonzalez-Gay, M. A. (2011) TNFA - 308 (rs1800629) polymorphism is associated with a higher risk of cardiovascular disease in patients with rheumatoid arthritis. Atherosclerosis 216, 125-130 CrossRef PubMed

24 Lacroix, R., Robert, S., Poncelet, P. and Dignat-George, F. (2010) Overcoming limitations of microparticle measurement by flow cytometry. Semin. Thromb. Hemost. 36, 807-818 CrossRef PubMed

25 Aass, H. C., Ovstebo, R., Troseid, A. M., Kierulf, P., Berg, J. P. and Henriksson, C. E. (2011) Fluorescent particles in the antibody solution result in false TF- and CD14-positive microparticles in flow cytometric analysis. Cytometry A 79, 990-999 CrossRef PubMed

26 Ayers, L., Kohler, M., Harrison, P., Sargent, I., Dragovic, R., Schaap, M., Nieuwland, R., Brooks, S. A. and Ferry, B. (2011) Measurement of circulating cell-derived microparticles by flow cytometry: sources of variability within the assay. Thromb. Res. 127, 370-377 CrossRef PubMed

27 Berckmans, R. J., Nieuwland, R., Tak, P. P., Boing, A. N., Romijn, F. P., Kraan, M. C., Breedveld, F. C., Hack, C. E. and Sturk, A. (2002) Cell-derived microparticles in synovial fluid from inflamed arthritic joints support coagulation exclusively via a factor VII-dependent mechanism. Arthritis Rheum. 46, 2857-2866 CrossRef PubMed

28 Knijff-Dutmer, E. A., Koerts, J., Nieuwland, R., Kalsbeek-Batenburg, E. M. and van de Laar, M. A. (2002) Elevated levels of platelet microparticles are associated with disease activity in rheumatoid arthritis. Arthritis Rheum. 46, 1498-1503 CrossRef PubMed

29 Sellam, J., Proulle, V., Jungel, A., Ittah, M., Miceli, R. C., Gottenberg, J. E., Toti, F., Benessiano, J., Gay, S., Freyssinet, J. M. and Mariette, X. (2009) Increased levels of circulating microparticles in primary Sjogren's syndrome, systemic lupus erythematosus and rheumatoid arthritis and relation with disease activity. Arthritis Res. Ther. 11, R156 CrossRef PubMed 
30 Iversen, L. V., Ostergaard, O., Ullman, S., Nielsen, C. T., Halberg, P., Karlsmark, T., Heegaard, N. H. and Jacobsen, S. (2013) Circulating microparticles and plasma levels of soluble E- and P-selectins in patients with systemic sclerosis. Scand. J. Rheumatol. 42, 473-482 CrossRef PubMed

31 Jimenez, J. J., Jy, W., Mauro, L. M., Soderland, C., Horstman, L. L. and Ahn, Y. S. (2003) Endothelial cells release phenotypically and quantitatively distinct microparticles in activation and apoptosis. Thromb. Res. 109, 175-180 CrossRef PubMed

32 Key, N. S. (2010) Analysis of tissue factor positive microparticles. Thromb. Res. 125 (Suppl. 1), S42-S45 CrossRef PubMed

33 Szodoray, P., Tarr, T., Tumpek, J., Kappelmayer, J., Lakos, G., Poor, G., Szegedi, G. and Kiss, E. (2009) Identification of rare anti-phospholipid/protein co-factor autoantibodies in patients with systemic lupus erythematosus. Autoimmunity 42, 497-506 CrossRef PubMed

34 Albanyan, A. M., Murphy, M. F., Rasmussen, J. T., Heegaard, C. W. and Harrison, P. (2009) Measurement of phosphatidylserine exposure during storage of platelet concentrates using the novel probe lactadherin: a comparison study with annexin V. Transfusion 49, 99-107 CrossRef PubMed

35 Bernimoulin, M., Waters, E. K., Foy, M., Steele, B. M., Sullivan, M., Falet, H., Walsh, M. T., Barteneva, N., Geng, J. G., Hartwig, J. H. et al. (2009) Differential stimulation of monocytic cells results in distinct populations of microparticles. J. Thromb. Haemost. 7, 1019-1028 CrossRef PubMed

36 Dasgupta, S. K., Abdel-Monem, H., Niravath, P., Le, A., Bellera, R. V., Langlois, K., Nagata, S., Rumbaut, R. E. and Thiagarajan, P. (2009) Lactadherin and clearance of platelet-derived microvesicles. Blood 113, 1332-1339 CrossRef PubMed

37 Enjeti, A. K., Lincz, L. and Seldon, M. (2008) Bio-maleimide as a generic stain for detection and quantitation of microparticles. Int. J. Lab. Hematol. 30, 196-199 CrossRef PubMed

38 Innala, L., Moller, B., Ljung, L., Magnusson, S., Smedby, T., Sodergren, A., Ohman, M. L., Rantapaa-Dahlqvist, S. and Wallberg-Jonsson, S. (2011) Cardiovascular events in early RA are a result of inflammatory burden and traditional risk factors: a five year prospective study. Arthritis Res. Ther. 13, R131 CrossRef PubMed

39 Symmons, D. P. and Gabriel, S. E. (2011) Epidemiology of CVD in rheumatic disease, with a focus on RA and SLE. Nat. Rev. Rheumatol. 7, 399-408 CrossRef PubMed

40 Del, R. I., Freeman, G. L., Haas, R. W., O'Leary, D. H. and Escalante, A. (2005) Relative contribution of cardiovascular risk factors and rheumatoid arthritis clinical manifestations to atherosclerosis. Arthritis Rheum. 52, 3413-3423 CrossRef PubMed

41 Wallberg-Jonsson, S., Johansson, H., Ohman, M. L. and Rantapaa-Dahlqvist, S. (1999) Extent of inflammation predicts cardiovascular disease and overall mortality in seropositive rheumatoid arthritis. A retrospective cohort study from disease onset. J. Rheumatol. 26, 2562-2571 PubMed
42 Hur, J., Yang, H. M., Yoon, C. H., Lee, C. S., Park, K. W., Kim, J. H., Kim, T. Y., Kim, J. Y., Kang, H. J., Chae, I. H. et al. (2007) Identification of a novel role of $\mathrm{T}$ cells in postnatal vasculogenesis: characterization of endothelial progenitor cell colonies. Circulation 116, 1671-1682 CrossRef PubMed

43 Ostergaard, O., Nielsen, C. T., Iversen, L. V., Tanassi, J. T., Knudsen, S., Jacobsen, S. and Heegaard, N. H. (2013) Unique protein signature of circulating microparticles in systemic lupus erythematosus. Arthritis Rheum. 65, 2680-2690 PubMed

44 Gyorgy, B., Szabo, T. G., Turiak, L., Wright, M., Herczeg, P., Ledeczi, Z., Kittel, A., Polgar, A., Toth, K., Derfalvi, B. et al. (2012) Improved flow cytometric assessment reveals distinct microvesicle (cell-derived microparticle) signatures in joint diseases. PLoS ONE 7, e49726 CrossRef PubMed

45 Berckmans, R. J., Nieuwland, R., Kraan, M. C., Schaap, M. C. Pots, D., Smeets, T. J., Sturk, A. and Tak, P. P. (2005) Synovial microparticles from arthritic patients modulate chemokine and cytokine release by synoviocytes. Arthritis Res. Ther. 7, R536-R544 CrossRef PubMed

46 Constans, J. and Conri, C. (2006) Circulating markers of endothelial function in cardiovascular disease. Clin. Chim. Acta 368, 33-47 CrossRef PubMed

47 Dessein, P. H., Joffe, B. I. and Singh, S. (2005) Biomarkers of endothelial dysfunction, cardiovascular risk factors and atherosclerosis in rheumatoid arthritis. Arthritis Res. Ther. 7, R634-R643 CrossRef PubMed

48 Boulanger, C. M., Scoazec, A., Ebrahimian, T., Henry, P., Mathieu, E., Tedgui, A. and Mallat, Z. (2001) Circulating microparticles from patients with myocardial infarction cause endothelial dysfunction. Circulation 104, 2649-2652 CrossRef PubMed

49 Distler, J. H., Akhmetshina, A., Dees, C., Jungel, A., Sturzl, M., Gay, S., Pisetsky, D. S., Schett, G. and Distler, O. (2011) Induction of apoptosis in circulating angiogenic cells by microparticles. Arthritis Rheum. 63, 2067-2077 CrossRef PubMed

50 Perez-Casal, M., Downey, C., Fukudome, K., Marx, G. and Toh, C. H. (2005) Activated protein $C$ induces the release of microparticle-associated endothelial protein $\mathrm{C}$ receptor. Blood 105, 1515-1522 CrossRef PubMed

51 Perez-Casal, M., Downey, C., Cutillas-Moreno, B., Zuzel, M., Fukudome, K. and Toh, C. H. (2009) Microparticle-associated endothelial protein $\mathrm{C}$ receptor and the induction of cytoprotective and anti-inflammatory effects. Haematologica 94, 387-394 CrossRef PubMed

52 Tans, G., Rosing, J., Thomassen, M. C., Heeb, M. J., Zwaal, R. F. and Griffin, J. H. (1991) Comparison of anticoagulant and procoagulant activities of stimulated platelets and platelet-derived microparticles. Blood 77, 2641-2648 PubMed

53 Mesri, M. and Altieri, D. C. (1998) Endothelial cell activation by leukocyte microparticles. J. Immunol. 161, 4382-4387 $\underline{\text { PubMed }}$ 